\title{
Editorial
}

\section{The British Paediatric Association, the British Medical Association, and the Archives}

The Archives began publication by the British Medical Association in 1926, and 2 years later the British Paediatric Association was founded. Although meetings of the BPA from 1928 onwards were reported in the Archives, rather surprisingly it was not until 1945 that an agreement was reached that the BPA should be responsible for nominating the Editors and the members of the Editorial Committee. (The story of the relationship between the BPA and the Archives is well told in H. C. Cameron's The British Paediatric Association, 1928-1952.) The resulting loose arrangement between the two Associations worked well over the subsequent 20 years, but the time came when it needed to be replaced by a more formal agreement.

The Archives is now jointly owned by the BPA and the BMA, and any profits are to be equally shared between the two partners. The BPA will continue to be responsible for appointing the Editors and the Editorial Committee. Through Dr Stephen Lock, Editor of the British Medical Journal, who is ex officio a member of the Editorial Committee, we look forward to maintaining the close, friendly, and fruitful links that we have long enjoyed with the BMA as publishers. 